\title{
Anti-hyperlipidemic effect of Vitex doniana in poloxamer induced hyperlipidemia
}

\begin{abstract}
To determine the effect of Vitex doniana (leaves stem and root bark) ethanol extracts on lipid profiles of Poloxamer 407 (P-407) induced hyperlipidemic and normal rats. Fifty four mixed sex rats weighing 100-200g were divided into nine groups comprising six animals per group: group given feed and water only, group induced by an intra-peritoneal injection of P-407 every 48hours without treatment, groups induced and treated with atorvastatin, leaves, stem bark, root bark extracts and groups of normal rats treated with leaves, stem bark and root bark extracts without induction. In all the groups, P-407, atorvastatin, leaves, stem bark and root bark extracts were administered at a dose of $1000 \mathrm{mg} / \mathrm{kg}, 20 \mathrm{mg} / \mathrm{kg}$, $100 \mathrm{mg} / \mathrm{kg}, 100 \mathrm{mg} / \mathrm{kg}$ and $30 \mathrm{mg} / \mathrm{kg}$ body weight respectively. At the end of the 21 day, the animals were sacrificed and blood sample were collected for determination of serum levels of: Total cholesterol (TC), Triacylglycerides (TAG), High-density lipoprotein cholesterol (HDL-c) and Low-density lipoprotein cholesterol (LDL-c). The studies showed that all induced treated groups significantly $(\mathrm{P}<0.05)$ lower serum levels of TC, TAG, LDL-c and significantly $(\mathrm{P}<0.05)$ increased HDL-c when compared to the $\mathrm{P} 407$ induced hyperlipidemic control. The normal treated groups showed no significant $(\mathrm{P}>0.05)$ difference in the serum levels of TC, TAG, LDL and HDL when compared to the normal control group. Calculation of atherogenic risk predictor indices of the induced treated groups showed that all the extracts significantly $(\mathrm{P}<0.05)$ lowered the LDL-c/HDL-c, log (TAG/HDL-c) and significantly $(\mathrm{P}<0.05)$ increased HDL-c/TC ratio when compared to the $\mathrm{P} 407$ induced hyperlipidemic control group. The atherogenic risk predictor indices of normal treated groups showed no significant difference $(\mathrm{P}>0.05)$ in LDL-c/HDL-c, Log (TAG/HDL-c) and HDL-c/TC ratio when compared to the normal control group. The study demonstrates the phytotherapeutic effect of Vitex doniana (leaves, stem and root bark) ethanol extract in poloxamer 407 induced hyperlipidemia.
\end{abstract}

Keywords: hyperlipidemia, poloxamer, vitex doniana, atorvastatin
Volume 3 Issue 4 - 2018

Victor Duniya Sheneni,Victor Akagwu Odiba,
Ameh Omede, Favour Moses Idih

Department of Biochemistry, Kogi State University, Nigeria

Correspondence: Sheneni Victor Duniya. Department of Biochemistry, Faculty of Natural Sciences, Kogi State University, PMB 1008,Anyigba, Nigeria, Tel +234- 8033519009,

Email shenenivictor@gmail.com

Received: August 13,2018| Published: September 25, 2018

\section{Introduction}

Hyperlipidemia is characterized by elevated serum total cholesterol, low density lipoprotein, very low density lipoprotein and decreased high density lipoprotein levels. It has been ranked as one of the greatest risk factors contributing to the prevalence and severity of coronary heart diseases. ${ }^{1}$ Coronary heart disease, stroke, atherosclerosis and hyperlipidemia are the primary cause of death. ${ }^{2}$ Hyperlipidemia associated lipid disorders are considered to cause atherosclerotic cardiovascular disease. ${ }^{3}$ Among these hypercholesterolemia and hypertriglyceridemia are closely related to ischemic heart disease. ${ }^{4}$ The main aim of treatment in patients with hyperlipidemia is to reduce the risk of developing ischemic heart disease or the occurrence of further cardiovascular disease or cerebrovascular disease. ${ }^{5}$ Currently available drugs have been associated with number of side effects and the consumption of synthetic drugs leads to hyperuricemic, diarrhoea, nausea, myositis, gastric irritation, flushing, dry skin and abnormal liver function. ${ }^{6}$

Poloxamer 407 (P-S407), a non-ionic surfactant is a block copolymer comprising of polyoxyethylene and polyoxypropylene units. It is known for its bio compatibility and potential to deliver different drugs for a variety of disease states, ${ }^{7}$ and as a barrier in preventing postsurgical adhesions. ${ }^{8}$ It has an unusual thermoreversible properties, it is liquid at room temperature while it self-assembles into micelles then aggregate into a gel at body temperature. These temperature-dependent micellization and gelation properties have led to the widespread use of P407 in personal care products such as mouthwashes, deodorants, and skin care products and also as an excipient in a variety of pharmaceutical preparations. ${ }^{9}$ Johnston, showed that one intramuscular or intraperitoneal injection of Poloxamer 407 causes dose-dependent hyperlipidemia in rats, increasing plasma triacylglycerol (TAG) more than 60 fold and cholesterol 8 fold and since then has been a growing model in different hyperlipidemic studies.

Plants appear to be the major source of drugs for the majority of the world's population, ${ }^{10}$ with substances derived from higher plants constituting about a quarter of all prescribed medicines. ${ }^{11}$ Several herbal medicines have advanced to clinical use in modern times. ${ }^{12} \mathrm{~A}$ medicinal plant is a plant that one or more of its part or organ contains substances that may be used for therapeutic purposes or as precursor for the synthesis of useful drugs. ${ }^{13}$ One of such plant is Vitex doniana.

Vitex doniana is a widely used plant in Nigerian traditional medicine; the plant belongs to the dicotyledonous family of Verbenaceae. Its local names in Nigeria include; Black plum (English), dinya (Hausa and Igala), Ucha-koro (Igbo) and Orin-ola (Yoruba). The tree average $20-25 \mathrm{~m}$ in height and $1 \mathrm{~m}$ in diameter has a wide spreading crown and a short stout trunk. It is slow growing with an average life span of 60-200years. Today, Vitex grows widely in most tropical and subtropical regions of the world, and is well adapted to semi-arid tropical conditions and also grow well in many humid tropical areas with seasonally high rainfall of $750-2000 \mathrm{~mm}$. It is cultivated commercially in variety of soils of varying origins, usually alluvial soils and homestead gardens for its product. ${ }^{14}$ The plant have been used as medication for infertility, liver disease, anodyne, 
stiffness, leprosy, backache, hemiplegia, rash, measles, infertility, anemia, jaundice, dysentery, hypertension, gonorrhea, headaches, diabetes, chickenpox, rash, fever, cancer, as tonic galactagogue to aid milk production in lactating mothers, sedative, digestive regulator and treatment of eye troubles, kidney troubles and as supplement for lack of vitamin A and B. ${ }^{15}$ Most of the biological activity of Vitex doniana has been attributed to the presence of a polyphenols. ${ }^{16}$

\section{Materials and methods}

\section{Kits}

All assays kits for Total cholesterol (TC), Triacylglycerol (TAG), High Density Lipoprotein (HDL) and Low Density Lipoprotein (LDL) were purchased from Randox laboratories Ltd ${ }^{\circledR}$ (Northern Ireland, UK), Ardmore, Co. Antrum UK.

\section{Animals}

A total of 54 apparently healthy Albino Wistar rats of both sexes weighing between $100-150 \mathrm{~g}$ were obtained from National Institute for Trypanosomiasis Research, Kaduna, Nigeria, and kept according to sexes in well aerated laboratory cages in the Animal house, Department of Pharmacology, Ahmadu Bello University, Zaria, Nigeria. The animals were allowed to acclimatize to the laboratory environment for a period of two weeks before the commencement of the experiment. They were fed with water and grower mash ad libitum.

\section{Collection of plant material and identification}

The Vitex doniana plants were collected from its natural habitat at the Institute of Agricultural Research (IAR), Ahmadu Bello University (ABU), Zaria, and Kaduna State in the month of April 2012, and authenticated at the Herbarium unit by Gallah U.J in the Department of Biological Sciences, Ahmadu Bello University, Zaria with a voucher number 1162 .

\section{Plant preparation and extraction}

The collected plant samples were rinsed in clean water and dried at room temperature for two weeks. The dried plant samples were grinded into powder using mortar and pestle, the powder obtained were used to prepare the extracts. $50 \mathrm{~g}$ of each of the grinded sample (leave, stem and root bark) were suspended in $500 \mathrm{ml}$ of ethanol for 48 hours at room temperature and filtered. The filtrates obtained were concentrated by drying in a water bath maintained at a temperature of 45 degree Celsius until brownish black residues were obtained. This were kept in a sealed container and refrigerated at 2-4 degree Celsius until required.

\section{Acute toxicity study $\left(\operatorname{LD}_{50}\right)$}

The mean lethal dose $\left(\mathrm{LD}_{50}\right)$ of Vitex doniana (leaves, stem and root bark) ethanol extract were determined by a method described by Lorke. ${ }^{17}$

\section{Preparation of standard drug}

Atorvastatin (Pfizer Ireland Pharmaceuticals, Ireland) was purchased in a tablet form at strength $20 \mathrm{mg}$. Tablets were crushed into powder, dissolved in distilled water and administered orally.

\section{Induction of hyperlipidemia}

Poloxamer 407 (Lutrol F127; BASF, Ludwigshafen, Germany) was used as the inducing agent. Hyperlipidemia was induced as described by Megalli. ${ }^{18}$ Briefly; $1.0 \mathrm{~g} / \mathrm{kg}$ dose of P-407 was introduced intraperitoneally. All syringes were placed on ice prior to P-407 administration to maintain the polymer in a mobile viscous state during the injection, since P407 solutions at concentrations greater than about $23 \% \mathrm{w} / \mathrm{w}$ exhibit reverse thermal gelatin properties.

\section{Animal grouping}

\section{Animal grouping and treatment}

A total of 54 healthy Albino Wistars rats were used. The rats were randomly divided into 9 groups of 6 rats each.

Group I: were fed with normal chow and distilled water only for 21days (NC).

Group II: were induced with $1.0 \mathrm{~g} / \mathrm{kg}$ dose of P-407 according to Megalli, ${ }^{18}$ without treatment (HC).

Group III: were induced with $1.0 \mathrm{~g} / \mathrm{kg}$ dose of P-407 and treated with Atorvastatin (ATV) at $20 \mathrm{mg} / \mathrm{kg}$ body weight/day for 21 days

Group IV: were induced with $1.0 \mathrm{~g} / \mathrm{kg}$ dose of P-407 and treated with leaves extract (HLE) at $100 \mathrm{mg} / \mathrm{kg}$ body weight/day for 21days

Group V: were induced with $1.0 \mathrm{~g} / \mathrm{kg}$ dose of P-407 and treated with stem bark extract extract (HSE) at $100 \mathrm{mg} / \mathrm{kg}$ body weight/ day for 21days

Group VI: were induced with $1.0 \mathrm{~g} / \mathrm{kg}$ dose of P-407 and treated with root bark extract extract (HRE) at $30 \mathrm{mg} / \mathrm{kg}$ body weight/day for 21 days

Group VII: were normal animals treated with leaves extract (NLE) at $100 \mathrm{mg} / \mathrm{kg}$ body weight/day for 21 days

Group VIII: were normal animals treated with stem bark extract (NSE) at $100 \mathrm{mg} / \mathrm{kg}$ body weight/day for 21 days

Group IX: were normal animals treated with root bark extract (NRE) at $30 \mathrm{mg} / \mathrm{kg}$ body weight/day for 21 days

The dose regimens were administered once daily for the period of the study. The rats were monitored for clinical signs and death.

\section{Collection and preparation of sera samples}

At the end of the 21-day experimental period, the chloroforminhalation anesthesia was performed on all experimental animals. The anesthetized animals were bled by cardiac puncture. The blood samples were collected and centrifuged at a speed of $3000 \mathrm{r} / \mathrm{m}$ for 15 minutes and serum collected into plain sample bottles for lipid analysis.

\section{Serum lipid analysis}

Total cholesterol (TC), high-density lipoprotein-cholesterol (HDL-c) and Triacylglycerol (TAG) were determined by enzymatic method as described by Stein $^{19}$ low-density lipoprotein cholesterol (LDL-c) was determined by the method of Friedewald, ${ }^{20}$ and atherogenic risk factor was calculated using formula of Dobiasova and Froehlich. ${ }^{21}$

\section{Data analysis}

Data are expressed as mean \pm standard deviation (SD) and were analyzed by the analysis of variance (ANOVA). The difference between the various ethanol extract and animal groups were compared using the Duncan Multiple Range Test. $P$ value less than 0.05 was considered significant $(P<0.05)$. 


\section{Results}

\section{Changes in lipid profile}

The effects of Vitex doniana (leaves, stem and root bark) ethanol extracts on lipid profile is shown in Table 1. The results shows that animals in the group induced without treatment shows a significant $(\mathrm{p}<0.05)$ increase in TC, TAG and LDL-c when compared with all other groups. All the animals in the groups treated with the extract without induction shows no significant $(\mathrm{P}>0.05)$ difference in $\mathrm{TC}$, TAG, LDL-c and HDL-c when compared with animals in the normal control group. Animals induced and treated shows that the leaves extract significantly $(\mathrm{p}<0.05)$ decreased the TC, TAG and LDL-c when compared to other induced treated groups. The HDL-c level in induced without treatment shows a significant $(\mathrm{p}<0.05)$ decrease when compared with all other groups. Animals induced and treated with leaves, stem and standard drug shows a significant $(\mathrm{p}<0.05)$ increase in HDL-c when compared with animals in the root treated group.

\section{Atherogenic risk predictor indices}

Table 2 shows the effects of Vitex doniana (leaves stem and root bark) ethanol extracts on serum atherogenic risk predictor indices of P407 induced hyperlipidemic and normal rats. The results shows that animals in group induced without treatment shows a significant $(\mathrm{P}<0.05)$ reduction in HDL-c/TC ratio, and increase in LDL-c/ HDL-c ratio and LOG (TG/HDL-c) ratio when compared with all other groups. All the animals in the groups treated with the extract without induction shows no significant $(\mathrm{P}>0.05)$ difference HDL-c/ TC, LDL-c/HDL-c and LOG (TG/HDL-c) ratio when compared with animals in the normal control group. Animals induced and treated shows that the leaves, stem bark and standard drug significantly $(\mathrm{P}<0.05)$ increased the HDL-c/TC ratio when compared to the root treated group. Similarly, animals induced and treated shows that the leaves significantly $(\mathrm{p}<0.05)$ decreased the LDL-c/HDL-c and LOG (TG/HDL-c) ratio when compared to other induced treated groups.

Table I Effects of Vitex Doniana Ethanolic Extract on Lipid Profiles of P407 Induced Hyperlipidemic and Normal Rats

\begin{tabular}{lllll}
\hline Group $(\mathbf{n}=6)$ & $\begin{array}{l}\text { Serum TC } \\
(\mathbf{m g} / \mathrm{dl})\end{array}$ & $\begin{array}{l}\text { Serum TAG } \\
(\mathbf{m g} / \mathbf{d l})\end{array}$ & $\begin{array}{l}\text { Serum HDL }-\mathrm{c} \\
(\mathbf{m g} / \mathrm{dl})\end{array}$ & $\begin{array}{l}\text { Serum LDL-c } \\
(\mathbf{m g} / \mathrm{dl})\end{array}$ \\
\hline $\mathrm{NC}$ & $143.73 \pm 4.75^{\mathrm{a}}$ & $126.77 \pm 13.30^{\mathrm{a}}$ & $63.37 \pm 0.66^{\mathrm{d}}$ & $41.75 \pm 5.34^{\mathrm{a}}$ \\
$\mathrm{HC}$ & $269.60 \pm 3.40^{\mathrm{a}}$ & $437.99 \pm 9.23^{\mathrm{e}}$ & $49.16 \pm 1.09^{\mathrm{a}}$ & $91.17 \pm 4.62^{\mathrm{d}}$ \\
$\mathrm{H}+\mathrm{SD}$ & $194.66 \pm 2.196^{\mathrm{c}}$ & $170.06 \pm 9.48^{\mathrm{c}}$ & $61.65 \pm 1.32^{\mathrm{c}}$ & $72.31 \pm 2.93^{\mathrm{b}}$ \\
$\mathrm{H}+\mathrm{LE}$ & $186.90 \pm 2.19^{\mathrm{b}}$ & $162.16 \pm 19.69^{\mathrm{b}}$ & $61.23 \pm 1.07^{\mathrm{c}}$ & $75.70 \pm 6.04^{\mathrm{b}}$ \\
$\mathrm{H}+\mathrm{SE}$ & $195.88 \pm 1.45^{\mathrm{c}}$ & $199.15 \pm 7.87^{\mathrm{c}}$ & $61.39 \pm 0.61^{\mathrm{c}}$ & $77.43 \pm 2.25^{\mathrm{bc}}$ \\
$\mathrm{H}+\mathrm{RE}$ & $207.76 \pm 1.50^{\mathrm{d}}$ & $224.88 \pm 13.18^{\mathrm{d}}$ & $59.72 \pm 0.33^{\mathrm{b}}$ & $82.51 \pm 3.76^{\mathrm{c}}$ \\
$\mathrm{N}+\mathrm{LE}$ & $142.27 \pm 5.01^{\mathrm{a}}$ & $123.56 \pm 15.46^{\mathrm{a}}$ & $63.48 \pm 0.35^{\mathrm{d}}$ & $41.04 \pm 6.36^{\mathrm{a}}$ \\
$\mathrm{N}+\mathrm{SE}$ & $143.24 \pm 5.34^{\mathrm{a}}$ & $126.77 \pm 14.63^{\mathrm{a}}$ & $63.58 \pm 0.33^{\mathrm{d}}$ & $41.48 \pm 6.44^{\mathrm{a}}$ \\
$\mathrm{N}+\mathrm{RE}$ & $143.75 \pm 3.52^{\mathrm{a}}$ & $125.17 \pm 13.18^{\mathrm{a}}$ & $63.37 \pm 0.35^{\mathrm{d}}$ & $42.07 \pm 5.70^{\mathrm{a}}$ \\
\hline
\end{tabular}

Values are mean $\pm S D$.Values with different superscripts down the column are significantly different $(p<0.05)$.

NC: Normal Control rat. HC: Lipid control rats. H+SD: Hyperlipidemic rats $+20 \mathrm{mg} / \mathrm{kg}$ Atorvastatin. H+LE: Hyperlipidemic rats $+100 \mathrm{mg} / \mathrm{kg}$ ethanolic leaf extract. $\mathrm{H}+\mathrm{SE}$ : Hyperlipidemic rats $+100 \mathrm{mg} / \mathrm{kg}$ ethanolic stem bark extract. H+RE: Hyperlipidemic rats $+30 \mathrm{mg} / \mathrm{kg}$ ethanolic root bark extract. N+LE: Normal rats $+100 \mathrm{mg} /$ $\mathrm{kg}$ ethanolic leave extract. $\mathrm{N}+\mathrm{SE}$ : Normal rats $+100 \mathrm{mg} / \mathrm{kg}$ ethanolic stem extract. $\mathrm{N}+\mathrm{RE}$ : Normal rats $+30 \mathrm{mg} / \mathrm{kg}$ ethanolic root bark extract.

TC, total cholesterol; TAG, triacylglycerol; HDL-c, high density lipoprotein; LDL-c, low density lipoprotein

Table 2 Effects of Vitex Doniana ethanolic extracts on atherogenic predictor indices of P407 induced hyperlipidemic and normal rats

\begin{tabular}{llll}
\hline Group $(\mathbf{n}=6)$ & HDL-c $/ T C$ & LDL-c/HDL-c & LOG $(T G / H D L-c)$ \\
\hline NC & $0.441 \pm 0.012^{d}$ & $0.658 \pm 0.081^{\mathrm{a}}$ & $0.299 \pm 0.044^{\mathrm{a}}$ \\
$\mathrm{HC}$ & $0.182 \pm 0.004^{\mathrm{a}}$ & $1.854 \pm 0.082^{\mathrm{d}}$ & $0.949 \pm 0.014^{\mathrm{e}}$ \\
$\mathrm{H}+\mathrm{SD}$ & $0.316 \pm 0.009^{\mathrm{c}}$ & $1.173 \pm 0.053^{\mathrm{b}}$ & $0.552 \pm 0.020^{\mathrm{c}}$ \\
$\mathrm{H}+\mathrm{LE}$ & $0.327 \pm 0.003^{\mathrm{c}}$ & $1.235 \pm 0.086^{\mathrm{b}}$ & $0.420 \pm 0.054^{\mathrm{b}}$ \\
$\mathrm{H}+\mathrm{SE}$ & $0.313 \pm 0.002^{\mathrm{c}}$ & $1.261 \pm 0.034^{\mathrm{b}}$ & $0.510 \pm 0.015^{\mathrm{c}}$ \\
$\mathrm{H}+\mathrm{RE}$ & $0.287 \pm 0.001^{\mathrm{b}}$ & $1.38 \mathrm{I} \pm 0.056^{\mathrm{c}}$ & $0.575 \pm 0.027^{\mathrm{d}}$ \\
$\mathrm{N}+\mathrm{LE}$ & $0.446 \pm 0.017^{\mathrm{d}}$ & $0.646 \pm 0.100^{\mathrm{a}}$ & $0.286 \pm 0.053^{\mathrm{a}}$ \\
$\mathrm{N}+\mathrm{SE}$ & $0.444 \pm 0.019^{\mathrm{d}}$ & $0.652 \pm 0.102^{\mathrm{a}}$ & $0.297 \pm 0.049^{\mathrm{a}}$ \\
$\mathrm{N}+\mathrm{RE}$ & $0.441 \pm 0.012^{\mathrm{d}}$ & $0.664 \pm 0.09 \mathrm{I}^{\mathrm{a}}$ & $0.293 \pm 0.044^{\mathrm{a}}$ \\
\hline
\end{tabular}

Values are mean $\pm S D$. Values with different superscripts down the column are significantly different $(p<0.05)$.

$\mathrm{NC}$, normal control rat; HC, lipid control rats; $\mathrm{H}+\mathrm{SD}$, hyperlipidemic rats $+20 \mathrm{mg} / \mathrm{kg}$ atorvastatin; $\mathrm{H}+\mathrm{LE}$, hyperlipidemic rats $+\mathrm{I} 00 \mathrm{mg} / \mathrm{kg}$ ethanolic leaf extract; $\mathrm{H}+\mathrm{SE}$, hyperlipidemic rats $+100 \mathrm{mg} / \mathrm{kg}$ ethanolic stem bark extract; $\mathrm{H}+\mathrm{RE}$, hyperlipidemic rats $+30 \mathrm{mg} / \mathrm{kg}$ ethanolic root bark extract; $\mathrm{N}+\mathrm{LE}$, normal rats $+100 \mathrm{mg} /$ $\mathrm{kg}$ ethanolic leave extract; $\mathrm{N}+\mathrm{SE}$, normal rats $+100 \mathrm{mg} / \mathrm{kg}$ ethanolic stem extract; $\mathrm{N}+\mathrm{RE}$, normal rats $+30 \mathrm{mg} / \mathrm{kg}$ ethanolic root bark extract.

TC, total cholesterol;TAG, triacylglycerol; HDL-c, high density lipoprotein; LDL-c, low density lipoprotein 


\section{Discussion}

Poloxamer 407, a non-ionic surfactant is well known to induce dose dependent hyperlipidemia ${ }^{22}$ by inhibiting capillary (heparin releasable) lipoprotein lipase (LPL), the major enzyme responsible for the hydrolysis of plasma lipoprotein triglycerides (TAG) and indirectly stimulating the activity of 3-hydroxy-3-methylglutaryl CoA (HMG $\mathrm{CoA})$ reductase, the rate limiting enzyme in cholesterol synthesis, thereby leading to hypertriglyceridemia and hypercholesterolemia respectively. Lipids are class of organic compounds that are fatty acids or their derivatives. They are insoluble in water but soluble in organic solvents. Lipids are known to perform a number of functions in the body which includes; chemical messengers, storage and provision of energy, maintenance of temperature and membrane lipid layer formation. ${ }^{23}$ However, abnormal elevations of lipids such as total cholesterol (TC), triglyceride (TAG) and low density lipoprotein cholesterol (LDL-c) results in a condition known as "Hyperlipidemia".

Hyperlipidemia is responsible for the onset and progression of atherosclerosis, ${ }^{24}$ a major risk factor in the development of coronary heart diseases (CHDs) such as ischemic heart disease, myocardial infarction and stroke. ${ }^{25}$ In clinical practice, effective and intensive lipid-lowering is important in order to reduce, ${ }^{26,27}$ and prevent CHDs. ${ }^{28}$ Vitex doniana (leaves, stem and root bark) ethanol extract significantly $(\mathrm{P}<0.05)$ reduced $\mathrm{TC}, \mathrm{TAG}$ and LDL-c concentrations. These reductions in TC, TAG and LDL levels suggest the ameliorative potential of Vitex doniana extracts in hyperlipidemia.

The elevation of TC concentration in this study was achieved by the indirect stimulation of HMG CoA reductase following an intraperitoneal (i.p) injection of P-407. ${ }^{29}$ Hence the possible TC lowering effects of Vitex doniana (leaves, stem and root bark) extracts could be attributed to decreased activity of hepatic HMG CoA reductase and/or stimulation of cholesterol-7-alpha-hydroxylase, which converts cholesterol into bile acids. It could also be due to the presence of saponins, a phytochemical which forms insoluble complexes with cholesterol or their bile salt precursor, thus making them unavailable for absorption. ${ }^{30}$ Besides, the standard drug (Atorvastatin) used in this study inhibits HMG CoA reductase, a rate limiting enzyme in the biosynthesis of cholesterol. The results obtained in this work conform to earlier report that polyphenols possesses antilipidemic activity. ${ }^{31}$

Increase in TAG concentration following P407 i.p. injection results primarily from an inhibition of TAG degradation, P407 directly inhibits capillary lipoprotein lipase (LPL) responsible for plasma TG hydrolysis. Although the standard drug might not decrease TAG concentrations by activating lipoprotein lipase, the ethanol extract from Vitex doniana could have reduced TAG levels by either activating endothelium bound lipoprotein lipase which hydrolyses the triglyceride into fatty acid hence decreasing triglyceride levels as seen in a report by Sikarwar and Patil ${ }^{32}$ or by inhibiting lipolysis so that fatty acids do not get converted to triglyceride.

LDL (low density lipoprotein) is responsible for transporting cholesterol to the body cells. It transports about $60-70 \%$ of total cholesterol. Therefore, an increase in TC level consequently increases LDL-c. The increased LDL-c which was not removed in the process of lipid metabolism is likely to flow into the sub-endothelial space, as well as to undergo oxidation. The oxidized LDL is phagocytized by the scavengers of macrophages and the fat-laden macrophage is left with the lipid core filled with cholesterol after necrocytosis and then arteriosclerosis is initiated. It was reported that some isoflavones (a type of flavonoid) increase resistance to LDL-c oxidation, like soybean isoflavones and genistein derivatives. This work also shows significant $(\mathrm{P}<0.05)$ reduction in LDL c levels by all Vitex doniana ethanol extract (Table 1). This result is in accordance with the work of Baum, ${ }^{33}$ who reported that phenolics may work by increasing LDL-c receptors densities in the liver binding to apolipoprotein B thereby making liver cells more efficient to remove LDL-C from blood.

HDL-c act as cholesterol scavengers, they pick up excess cholesterol and cholesterol esters from the blood and peripheral tissues to the liver where it is broken down to bile acids. It plays an important role in reducing blood and peripheral cholesterol concentrations and inhibits formation of atherosclerotic plaque in the aorta, ${ }^{34,35}$ therefore known as the protective cholesterol. The present studies shows significant $(\mathrm{P}<0.05)$ increase in HDL-c by the standard drug, leaves and stem bark extracts. This could possibly be due to increasing activity of lecithin-cholesterol acyl transferase (LCAT), an enzyme responsible for incorporating free cholesterol into HDL-c as suggested by Geetha ${ }^{35}$ there by promoting reverse cholesterol transport and competitively inhibiting the uptake of LDL-c by endothelial cells and preventing the generation of oxidized LDL-c. ${ }^{36}$

Atherogenic risk predictor indices (HDL-c/TC, LDL-c/HDL-c and $\log$ (TG/HDL-c) are mathematical relationships between TC, TG, LDL-c and HDL-c that have been successfully used as markers of assessing atherosclerosis development, ${ }^{37,38}$ and extent of CHDs. HDL-c/ TC ratio greater than 0.3 and LDL-c/HDL-c ratio less than 2.3 indicate a reduced risk of peripheral arterial disease. ${ }^{39}$ However, log (TG/HDL-c) has been considered the most accurate in determining the extent of atherosclerosis and the risk of myocardial infarction. ${ }^{40}$ It has been suggested that $\log$ (TG/HDL-c) values of -0.3 to $0.1,0.1$ to 0.24 and above 0.24 are associated with low, medium and high cardiovascular risk disease. ${ }^{41}$ The study showed that the leaves, stem bark and root bark extract significantly $(\mathrm{P}<0.05)$ increased HDL-c/ TC ratio, and lowered LDL-c/HDL-c and $\log$ (TG/HDL-c) ratio when compared with animals in the induced not treated group. The results suggest the anti-atherogenic potential of Vitex doniana (leaves, stem and root bark) ethanol extracts and hence, reducing the development of coronary atherosclerosis as suggested by Dobiasova and Frohlich. ${ }^{42}$

\section{Conclusion}

In conclusion, the present study has demonstrated that Vitex doniana has anti-hyperlipidemic effects in Poloxamer induced hyperlipidemia. Utilizing this model, Vitex doniana was shown to be effective in significantly lowering total cholesterol, triglycerides and low density lipoprotein levels; thus it can be used in the treatment and/or prevention of cardiovascular diseases. However, more work is needed to investigate the anti-hyperlipidemic component(s) in Vitex doniana and mechanism of action.

\section{Acknowledgements}

None.

\section{Conflict of interest}

Author declares there is no conflict of interest towards this manuscript. 


\section{References}

1. Grundy SM. Cholesterol and coronary heart disease: a new era. JAMA. 1986;256(20):2849-2858.

2. Smith GD, Song F, Sheldon TA. Cholesterol lowering and mortality: the importance of considering initial level of risk. Int Med J. 1993;306(6889):1367-1373.

3. Saravanan R, Rajendra Prasad N, Pugalendi KV. Effect of Piper betle leaf extract on alcoholic toxicity in the rat brain. J Med Food. 2003;6(3):261265 .

4. Kaesancini AY. Krauss RM. Cardiovascular disease and hyperlipidemia. Cur Opinion in lipidolo. 1994;5:249-251.

5. Davey Smith G, Pekkanen J. Should there be a moratorium on the use of cholesterol lowering drugs? Br Med J. 1992;304(6824):431-440.

6. Brown SL. Lowered serum cholesterol and low mood: $B M J$. 1996;313(7058):637-638.

7. Johnston TP, Punjabi MA, Froelich CJ. Sustained delivery of interleukin-2 from a poloxamer-407 gel matrix following intraperitoneal injection in mice. Pharm Res. 1992;9(3):425-434.

8. Steinleitner A, Lambert H, Kazensky C, et al. Poloxamer-407 as an intraperitoneal barrier material for the prevention of postsurgical adhesion formation and reformation in rodent models for reproductive surgery. Obstet Gynecol. 1991;77(1):48-52.

9. Dumortier G, Grossiord JL, Agnely F, et al. A review of poloxamer 407 pharmaceutical and pharmacological Characteristics. Pharm Res. 2006;23(12):2709-2728.

10. Oluyemi KA, Omotuyi IO, Jimoh OR, et al. Erythropoietic and antiobesity effects of Garcinia cambogia (bitter kola) in Wistar rats. Biotechnol Appl Biochem. 2007;46(Pt 1):69-72.

11. Kumar S, Kumar R, Khan A. Medicinal Plant Resources: Manifestation and Prospects of Life sustaining Healthcare System. Conti. J of Biolo Sci. 2011;4(1):19-29.

12. Mahmood ZA1, Sualeh M, Mahmood SB, et al. Herbal treatment for cardiovascular disease the evidence based therapy. Pak $J$ of Pharmace Sci. 2010;23(1):119-124.

13. World Health Organization (WHO). Medicinal plants and the pharmaceutical industry. New Crops. Wiley, New York: World Health Organization; 1998.

14. Food and Agriculture Organization (FAO). Food and fruit bearing forest species from Eastern Africa. Italy: FAO Forestry; 1983.

15. Sofowora EA. Medical plant and traditional remedies in African. Nigeria: University of lle-Ife press Nigeria; 1993. p. 1-23.

16. Quideau S, Deffieux D, Douat-Casassus C, et al. Plant polyphenols: chemical properties, biological activities, and synthesis. Angew Chem Int Ed Engl. 2011;50(3):586-621.

17. Lorke D. A new approach to practical acute toxicity testing. Arch Toxicol. 1983;54(4):275-287.

18. Megalli S, Aktan F, Davies NM, et al. Phytopreventative antihyperlipidemic effects of Gynostemma pentaphyllum in rats. J Pharm Set. 2005;8(3):507-515.

19. Stein EA. Lipids, lipoproteins and Apolipoproteins. In: Treitz NW, (editor). Fundamentals of Clinical Chemistry. $3^{\text {rd }}$ ed, Philadelphia: WB Sauders; 1987. p. 470-479.

20. Friedewald WT. Methods for the determination of LDL Cholesterol. Clin Chem. 1972;18:499-502.
21. Dobiásová M, Frohlich J. The plasma parameter Log (TG/HDLC) as an atherogenic index: correlation with lipoprotein particle size and etherification rate in apoB-lipoprotein-depleted plasma (FERHDL). Clin Biochem. 2001;34(7):583-538.

22. Johnston TP. The P-407-induced murine model of dose-controlled hyperlipidemia and atherosclerosis: A review of findings to date. $J$ Cardiovasc Pharmacol. 2004;43(4):595-606.

23. Akoh CC. Handbook of Functional Lipids. CRC Press, Athens, USA: the University of Georgia; 1994. 544 p.

24. Pöss J, Custodis F, Werner C, et al. Cardiovascular disease and dyslipidemia: Beyond LDL. Curr Pharm Des. 2011;17(9):861-870.

25. Vaziri ND, Norris K. Lipid disorders and their relevance to outcomes in chronic kidney disease. Blood Purif. 2011;31(1-3):189-196.

26. Murphy SA, Cannon CP, Wiviott SD, et al. Effect of intensive lipid lowering therapy on mortality after acute coronary syndrome (a patientlevel analysis of the Aggrastat to Zocor and Pravastatin or Atorvastatin Evaluation and Infection Therapy-Thrombolysis in Myocardial Infarction (22 trials). Am J Cardiol. 2007;100(7):1047-1051.

27. Nissen SE, Tuzcu EM, Schoenhagen P, et al. Effect of intensive compared with moderate lipid lowering therapy on progression of coronary atherosclerosis. JAMA. 2011;291(9):1071-1080.

28. Abdulazeez M. Effect of Peristrophe bicalyculata on lipid profile of $\mathrm{P}-407-$ induced hyperlipidemic Wistar rats. $J$ Med. Plants Res. 2011;5(4):490-494.

29. Messina MJ. Legumes and soybeans: Overview of their nutritional profiles and health effects. Am J Clin Nutr. 1999;70(3):439-450.

30. Beckmann N, Cannet C, Babin AL, et al. In vivo visualization of macrophage infiltration and activity in inflammation using magnetic resonance imaging. Wiley Interdiscip Rev Nanomed Nanobiotechnol. 2009; 1(3):272-298.

31. Sikarwar MS, Patil MB. Antihyperlipidemic Effect of Ethanolic Extract of Hibiscus rosa sinensis Flowers in Hyperlipidemic Rats. RGUHS J. of Pharmaceu Sci. 2011;1(2):117-122.

32. Baum JA. Teng H, Erdman JW, et al. Long-term intake of soy protein improves blood lipid profiles and increases mononuclear cell lowdensity-lipoprotein receptor messenger RNA in hypercholesterolemic, postmenopausal women. Am J Clin Nutr. 1998;68(3):545-551.

33. Kim HY, Jeong DM, Jung HJ, et al. Hypolipidemic Effects of Sophoraflavescens andIts Constituents in Poloxamer 407- Induced Hyperlipidemic and Cholesterol-Fed Rats. Biol Pharm Bul. 2008;31(1):73-78.

34. http://www.pharmainfo.net

35. Geetha G, Kalavalarasariel GP, Sankar V. Antidiabetic effect of Achyranthesrubrofusca leaf extracts on alloxan induced diabetic rats. Pak J Pharm Sci. 2011;24(2):193-199.

36. Yokozawa T, Cho EJ, Sasaki S, et al. The protective role of Chinese prescription kangen-karyu extract on diet-induced hypercholesterolemia in rats. Biol Pharm Bull. 2006;29(4):760-765.

37. Nicholls SJ1, Tuzcu EM, Sipahi I, et al. Statins, high-density lipoprotein cholesterol, and regression of coronary atherosclerosis. JAMA. 2007;297(5):499-508.

38. Kastelein JJ, van der Steeg WA, Holme I, et al. Lipids apolipoproteins and their ratios in relation to cardiovascular events with statin treatment. Circulation. 2008;117(23):3002-3009.

39. Ojiakor A, Nwanjo H. Effect of vitamine $\mathrm{E}$ and $\mathrm{C}$ on exercise induced oxidative stress. Global J of Pure Applied Sci. 2006;12(2):199-202. 
40. Dobiásová M, Urbanová Z, Samánek M. Relation between particle size of HDL and LDL Lipoproteins and cholesterol Esterification rate. Physiol Res. 2005;54(2):159-165.

41. Dobiasova M. AIP-atherogenic index of plasma as a significant predictor of cardiovascular risk: from research to practice. Vnitr Lek. 2006;52(1):64-71.
42. Dobiásová M, Frohlich J. The plasma parameter Log (TG/HDLC) as an atherogenic index: correlation with lipoprotein particle size and etherification rate in apoB-lipoprotein-depleted plasma (FERHDL). Clin Biochem. 2001;34(7):583-588. 